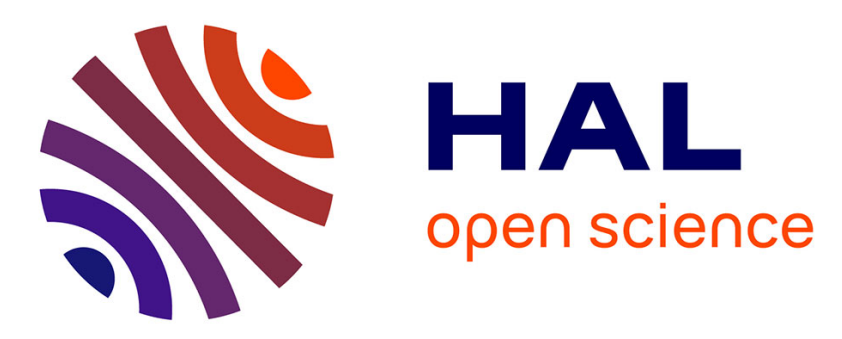

\title{
Selectivity Modulation and Structure of alpha/aza-beta(3) Cyclic Antimicrobial Peptides
}

Mathieu Laurencin, Matthieu Simon, Yannick Fleury, Michele Baudy-Floc'H, Arnaud Bondon, Baptiste Legrand

\section{- To cite this version:}

Mathieu Laurencin, Matthieu Simon, Yannick Fleury, Michele Baudy-Floc'H, Arnaud Bondon, et al.. Selectivity Modulation and Structure of alpha/aza-beta(3) Cyclic Antimicrobial Peptides. Chemistry - A European Journal, 2018, 24 (23), pp.6191-6201. 10.1002/chem.201800152 hal-01807077

\section{HAL Id: hal-01807077 https://hal-univ-rennes1.archives-ouvertes.fr/hal-01807077}

Submitted on 19 Jun 2018

HAL is a multi-disciplinary open access archive for the deposit and dissemination of scientific research documents, whether they are published or not. The documents may come from teaching and research institutions in France or abroad, or from public or private research centers.
L'archive ouverte pluridisciplinaire $\mathbf{H A L}$, est destinée au dépôt et à la diffusion de documents scientifiques de niveau recherche, publiés ou non, émanant des établissements d'enseignement et de recherche français ou étrangers, des laboratoires publics ou privés. 


\title{
Selectivity Modulation and Structure of $\alpha / a z a-\beta^{3}$ Cyclic Antimicrobial Peptides
}

\author{
Mathieu Laurencin ${ }^{[b, d]}$, Matthieu Simon ${ }^{[a, b, d]}$, Yannick Fleury ${ }^{[c]}$, Michèle Baudy-Floc' $h^{[b]}$, Arnaud \\ Bondon $^{[b]}$, Baptiste Legrand ${ }^{*[a, b]}$
}

\begin{abstract}
We successfully developed potent and selective antimicrobial cyclic pseudopeptides (ACPPs) mixing $\alpha$ - and aza- $\beta^{3}$ amino acids. Cyclopseudopeptide sequences were design in order to investigate the impact of some intrinsic molecular parameters on their biological activities. Fine changes in the nature of the side chains strongly modulated the ACPPs selectivity, hemolysis versus antimicrobial activities. We extensively studied the conformational preference of such kind of compounds in various media and described for the first time, the typical structure of cyclic $\alpha / a z a-\beta^{3}$ pseudopeptides. Interestingly, such scaffold were stabilized by successive inverse $\gamma$ - and $\mathrm{N}-\mathrm{N}$ turns (or hydrazinoturns), a unique feature driven by the aza- $\beta^{3}$ residues. The $\alpha$-amino acid side chains formed a cluster on one face of the cycle while the aza- $\beta^{3}$-amino acids side chains were projected around the ring in the equatorial orientation. Such structural data are particularly valuable to finely tune the bioactivity of these ACPPs using a structure-based approach.
\end{abstract}

\section{Introduction}

The emergence of bacterial pathogens that are resistant to conventional antibiotics is a growing public health threat. ${ }^{[1]}$ The current set of antibiotic agents is becoming incapable of combating many pathogenic bacteria, creating an unfortunate synergy of increased drug resistance combined with a diminishing rate of new antibiotic development. ${ }^{[2,3]}$ Thus, not only new antibiotic agents must be discovered but, in order to properly address antimicrobial resistance, these new antibiotics must also possess novel mechanisms of action. ${ }^{[4]}$ The proper selection of

[a] Dr. M. Simon, Dr. B. Legrand

Institut des Biomolécules Max Mousseron

UMR CNRS-UM-ENSCM 5247, UFR des sciences pharmaceutiques et Biologiques

15 Avenue Charles Flahault

34093 Montpellier Cedex 5 (France)

E-mail: baptiste.legrand@umontpellier.fr

[b] Dr. M. Baudy-Floc'h, Dr. A. Bondon, Dr. M. Laurencin, Dr M. Simon, Dr. B. Legrand

Univ Rennes, CNRS, ISCR - UMR 6226, F-35000 Rennes, France

[c] Dr. Y. Fleury

Université de Brest, EA 3884,

Chimie Marines, IUEM,

6 rue de l'Université, F-29000 Quimper (France)

[d] M. Laurencin and M. Simon contributed equally to this work. the antibiotic target is an essential consideration. In particular, targets that exhibit a low propensity for rapid resistance selection may lead to therapeutic regimens with sustained clinica efficacy. ${ }^{[5]}$ Previous studies have explored the use of hostdefense antimicrobial peptides (AMPs) that primarily target the bacterial membrane as novel antibiotic agents. ${ }^{[6-8]}$ AMPs have been studied as potential therapeutic agents owing to the low frequency of bacterial resistance observed for this class of compound. . $^{[5-11]}$ Most AMPs interact with and disrupt the bacterial cell membrane, triggering cell death. ${ }^{[12]}$ Accordingly, a common feature found among AMPs is their amphiphilic structure, wherein residues are segregated into hydrophobic and cationic regions. Their amphiphilic properties allow both the initial electrostatic interaction with the anionic bacterial phospholipid head groups and strong hydrophobic interactions with the apolar lipid acyl chains. The cationic nature of AMPs promote the AMPs selectivity for the negatively charged bacterial membranes rather than zwitterionic eukaryotic membranes. ${ }^{[13]}$ However, the entry of AMPs into clinical use has been hampered by poor selectivity and by in vivo degradation that can impair bioavailability. ${ }^{[14]}$

Extensive research efforts have sought to harness and enhance the desirable features present in naturally occurring AMPs. ${ }^{[15-17]}$ Peptidomimetic compounds can recapitulate the structure and function of natural AMPs while circumventing their susceptibility to protease degradation. ${ }^{[18]} \beta$ - and $\gamma$-peptides, ${ }^{[19-32]}$ peptoids, ${ }^{[3-36]}$ $\beta$-peptoids ${ }^{[37,38]}$ and oligoureas ${ }^{[39]}$ have generated significant interest as potential therapeutic agents, especially since they can adopt stable and predictable secondary structures and are anticipated to disturb the bacterial cell membrane similarly to AMPs. Our investigations focused on the incorporation of aza- $\beta^{3}$ amino acids in natural peptide sequences to modulate their bioavailability and activity. Linear and cyclic aza- $\beta^{3}$-peptides can adopt well-defined conformations stabilized by hydrogen bond network leading to bifidic eight membered ring pseudocycles forming hydrazinoturns or N-N turns in the solid-state and in organic media. ${ }^{[40,41]}$ Although the aza- $\beta^{3}$-amino acid nitrogen stereocenter bearing the side chains is nonfixed and can adopt the L- or D-configuration, the cyclic constraint significantly reduces the nitrogen inversion rate. Indeed, it has previously been showed that the configuration of the nitrogen can be controlled in cyclic aza- $\beta^{3}$-peptides. ${ }^{[42]}$

First, we developed strategies to synthesize large series of aza$\beta^{3}$-amino acids bearing proteogenic or non-proteogenic side chains suitable for straightforward solid phase peptide synthesis. ${ }^{[43-46]}$ Then, we showed that aza- $\beta^{3}$-amino acids containing peptides can exert various biological activities ${ }^{[47-49]}$ 
and we synthesized highly stable AMP mimicry with enhanced antimicrobial activities. ${ }^{[50-52]}$

A

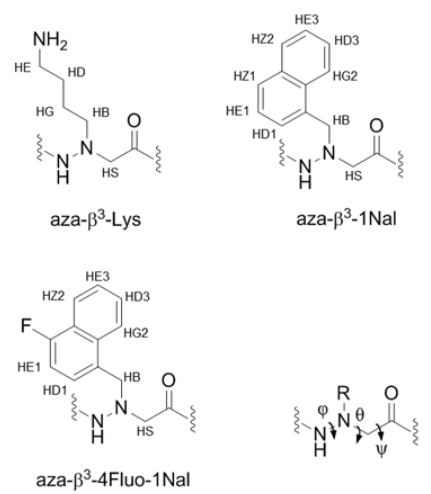

B

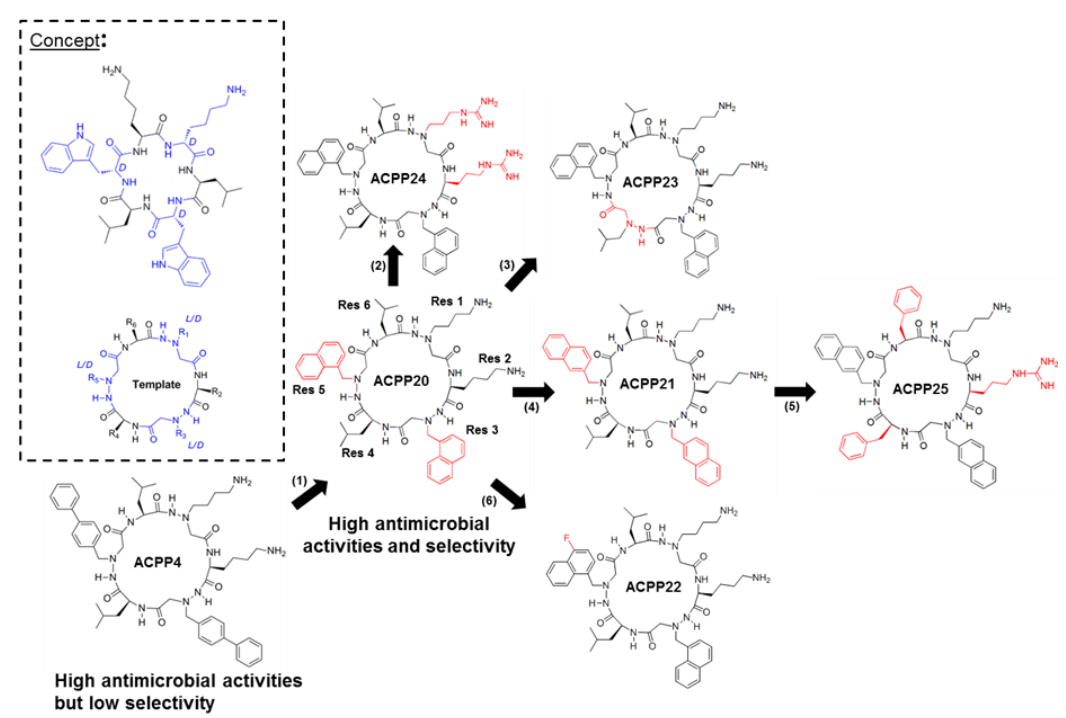

Figure 1. Design of cyclic pseudopeptide sequences. A) Aza- $\beta^{3}$-amino acid structures and their designators used in this study: aza- $\beta^{3}$-Leu: aza- $\beta^{3}$-Leucine; aza$\beta^{3}-1 \mathrm{Nal}$ : aza- $\beta^{3}-1$-Naphthylalanine; aza- $\beta^{3}-2 \mathrm{Nal}$ : aza- $\beta^{3}-2-$ Naphthylalanine; aza- $\beta^{3}$-Lys: aza- $\beta^{3}$-Lysine; aza- $\beta^{3}$-Arg: aza- $\beta^{3}-$ Arginine; aza- $\beta^{3}-4$ Fluo-1Nal: aza- $\beta^{3}-4-$ Fluoro-1-Nahphtylalanine. B) Antimicrobial L/D-cyclopeptide reported by Ghadiri et al. ${ }^{[53]}$ (top left), and the highly hemolytic ACPP4 ${ }^{[51]}$ (bottom left). ACPP sequences synthesized. (1) ACPP20: aza- $\beta^{3}$-1Bip $\rightarrow$ aza- $\beta^{3}-1$ Nal; (2) ACPP24: Lys/ aza- $\beta^{3}$-Lys $\rightarrow$ Arg/ aza- $\beta^{3}$-Arg; (3) ACPP23: Leu $4 \rightarrow$ aza- $\beta^{3}-$ Leu; (4) ACPP21: aza- $\beta^{3}-1$ Nal $\rightarrow$ aza- $\beta^{3}-2 \mathrm{Nal}$; (5) ACPP25: Leu $\rightarrow$ Phe; Lys $\rightarrow$ Arg; (6) ACPP22: aza- $\beta^{3}-1$ Nal $5 \rightarrow$ aza- $\beta^{3}-4$ Fluo-1Nal.

The large variety of side chains available allowed us to design various aza- $\beta^{3}$-peptidomimetic sequences while the abiotic moieties confer resistance against proteolytic degradation. Indeed, when incorporated into a linear peptide, aza- $\beta^{3}$-amino acids are known to enhance the resistance of the pseudopeptide to enzymatic degradation and, we showed that cyclic pseudopeptides share high metabolitic stability with a long halflife. ${ }^{[48,51]}$ Significantly, the insertion of aza- $\beta^{3}$-amino acids in peptide sequences can also induce hydrazinoturns in aqueous media and we investigated the structure-activity relationship of linear antimicrobial aza- $\beta^{3}$ peptidomimetics. ${ }^{[50]}$ While the mixed backbones can exhibit well-

defined structures, the most active compounds were rather flexible feeding the ongoing debate whether stable conformations are advantageous or deleterious for antimicrobial activity in peptidomimetic systems ${ }^{[54]}$.

Table 1. Analytical data on cyclopseudopeptide sequences ACPP 20-25

\begin{tabular}{|c|c|c|c|c|c|c|}
\hline \multirow{2}{*}{ ACPP } & \multirow{2}{*}{ Cyclopseudopeptide Sequences } & \multicolumn{2}{|c|}{ RP-HPLC $[\mathrm{a}]$} & \multicolumn{2}{|c|}{ Mass spectrometry } & \multirow{2}{*}{$\begin{array}{c}\text { Yields } \\
(\%)\end{array}$} \\
\hline & & $R_{\mathrm{t}}(\min )$ & purity (\%) & calcd $^{[b]}$ & $\mathrm{obs}^{[\mathrm{c}]}$ & \\
\hline 20 & $c\left[\right.$ aza- $\beta^{3}$ Lys-Lys-aza- $\beta^{3}-1$ Nal-Leu-aza- $\beta^{3}-1$ Nal-Leu $]$ & 20.6 & 99.9 & 922.56 & 922.32 & 41 \\
\hline 21 & $c\left[\right.$ aza- $\beta^{3}$ Lys-Lys-aza- $\beta^{3}-2 \mathrm{Nal}$-Leu-aza- $\beta^{3}-2 \mathrm{Nal}$-Leu] & 23.0 & 99.8 & 922.56 & 922.32 & 32 \\
\hline 22 & $c\left[\right.$ aza- $\beta^{3}$ Lys-Lys-aza- $\beta^{3}-1$ Nal-Leu-aza- $\beta^{3}-4$ Fluo-1Nal-Leu $]$ & 25.0 & 99.9 & 940.55 & 940.18 & 53 \\
\hline 23 & $c\left[\right.$ Lys-aza- $\beta^{3}$ Lys-Leu-aza- $\beta^{3}-1 \mathrm{Nal}-\mathrm{aza}-\beta^{3}$ Leu-aza- $\left.\beta^{3} 1 \mathrm{Nal}\right]$ & 21.6 & 99.7 & 937.57 & 937.21 & 40 \\
\hline 24 & $c\left[\right.$ aza- $\beta^{3}$ Arg-Arg-aza- $\beta^{3}-1$ Nal-Leu-aza- $\beta^{3}-1$ Nal-Leu $]$ & 21.7 & 99.9 & 978,57 & 978,39 & 52 \\
\hline 25 & $c\left[\right.$ aza- $\beta^{3}$ Lys-Arg-aza- $\left.\beta^{3}-2 \mathrm{Nal}-\mathrm{Phe}-\mathrm{aza}-\beta^{3}-2 \mathrm{Nal}-\mathrm{Leu}\right]$ & 24.8 & 99.7 & 1018.53 & 1017.93 & 38 \\
\hline
\end{tabular}

[a] Analytical HPLC analysis(see experimental section). [b] Theoretical monoisotopic molecular weight. [c] The m/z value assessed by HR-MS, ESI 
More recently, considering the relative abundance of natural and artificial cyclic AMPs, we designed hybrid cyclopseudopeptides composed of $L-\alpha$-amino acids and aza- $\beta^{3}$-amino acids. In a preliminary study, we showed that six-membered cycles bearing two positive charges were optimal for the antimicrobial activity and selectivity. The use of non-proteogenic hydrophobic side chains highly improved the antimicrobial activity and the proteolytic stability, but can also lead to highly toxic compounds on red blood cells (RBCs). ${ }^{\left[{ }^{[1]}\right.}$

In this work, we developed potent and selective cyclic mixed $\alpha /$ aza- $\beta^{3}$-peptides of which the sequences were optimized from these previous observations. We started from the most active compound (ACPP4) we previously obtained ${ }^{[51]}$, which was unfortunately highly hemolytic to develop the lead compound (ACPP20) of which the toxicity dramatically dropped while the antimicrobial activity remained substantial. Then, five more peptides (ACPP21-25) were synthesized to investigate the impact of the $\alpha /$ aza- $\beta^{3}$-amino acids alternation on the properties of the ACPPs and when varying the kind of aromatic rings and cationic side chains. We recorded circular dichroism (CD) spectra of all compounds in phosphate buffer and in membrane-mimicking media (micelles and SUVs). Then, we focused on ACPP20 and its fluorinated derivative ACPP22. We recorded transmission electron microscopy (TEM) micrographs to get new insights into their mode of action. Finally, a detailed nuclear magnetic resonance (NMR) analysis was performed in order to correlate the structure and the activities of such class of compound.

Table 2. MICs in $\mu \mathrm{M}$ against Gram-negative and Gram-positive bacteria and hemolytic activities against SRBC of tested ACPPs

\begin{tabular}{|c|c|c|c|c|c|c|c|c|}
\hline & & \multirow{2}{*}{$\begin{array}{l}\text { Control } \\
\text { Melittin }\end{array}$} & \multicolumn{6}{|c|}{ ACPPs } \\
\hline & & & 20 & 21 & 22 & 23 & 24 & 25 \\
\hline \multirow{7}{*}{ 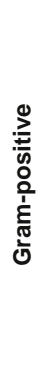 } & B. megaterium & 6.25 & 3.12 & 3.12 & 3.12 & 3.12 & 1.56 & 1.56 \\
\hline & E. faecalis & 12.5 & 50 & 50 & 25 & 50 & 25 & 12.5 \\
\hline & S. equinus & 3.12 & 6.25 & 6.25 & 6.25 & 6.25 & 3.12 & 3.12 \\
\hline & M. luteus & 1.56 & 3.12 & 3.12 & 3.12 & 3.12 & 3.12 & 3.12 \\
\hline & L. garvieae & 6.25 & 50 & 50 & 25 & 50 & 12.5 & 6.25 \\
\hline & L. monocytogenes & 3.12 & 12.5 & 12.5 & 6.25 & 12.5 & 6.25 & 3.12 \\
\hline & S. aureus & 25 & 25 & 25 & 12.5 & 25 & 12.5 & 3.12 \\
\hline \multirow{8}{*}{ 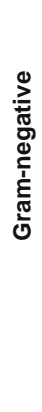 } & E. coli & 6.25 & 50 & 50 & 25 & 25 & 12.5 & 25 \\
\hline & S. enterica & 25 & 50 & 50 & 50 & 50 & 25 & 50 \\
\hline & P. aeruginosa & 50 & 50 & 50 & 25 & 100 & 50 & 12.5 \\
\hline & K. oxytoca & 25 & 50 & 50 & 25 & 25 & 25 & 25 \\
\hline & E. aerogenes & 12.5 & 25 & 50 & 50 & 50 & 25 & 50 \\
\hline & A. caviae & $>100$ & $>100$ & $>100$ & $>100$ & $>100$ & $>100$ & $>100$ \\
\hline & \multicolumn{2}{|c|}{$\mathrm{HC}_{50}$ on sRBC } & $>100$ & $>100$ & $>100$ & $>100$ & $>100$ & 100 \\
\hline & \multicolumn{2}{|c|}{$\%$ Hemolysis at $100 \mu \mathrm{M}$} & 1.5 & 8 & 5 & 6 & 12 & 50 \\
\hline
\end{tabular}

\section{Results and Discussion}

We previously designed antimicrobial cyclic aza- $\beta^{3}$-peptides with promising activities (i.e. ACPP4- $7^{[51]}$ ) based on cyclic antibacterial peptides alternating $D$ - and $L-\alpha$-amino acids described by Ghadiri and coworkers ${ }^{[53]}$. Among the 13 pseudopeptides synthesized, ACPP4 was the most potent compound but its high cytotoxicity limits its use as an antibacterial agent (Figure 1B) ${ }^{[51]}$. In this context, we reported herein, a pseudopeptide library consisting of six hexapseudopeptides composed with $\alpha$-L-amino acids and aza- $\beta^{3}$-amino acids and designed with sufficiently close sequences to investigate the impact of some intrinsic molecular parameters on their biological activities (ACPP20-25, Table 1 and Figure 1). We determined an optimal ratio between hydrophilic cationic and hydrophobic residues (2 cationic and 4 hydrophobic residues). We first designed ACPP20 as the reference of this study and then various derivatives were synthesized modifying the cationic and hydrophobic groups or the aza- $\beta^{3}$-amino acid content. ACPP20 bore two cationic lysyl side chains that were sufficient to target the negatively charged bacterial membranes. Among the four hydrophobic residues, two naturally occurring $\alpha$ leucine were alternated with nonproteinogenic synthetic aza- $\beta^{3}-1$ naphthylalanine especially designed and incorporated to enhance the ACPPs antimicrobial activities. Except ACPP23, all these pseudopeptide sequences alternated $\alpha$ - and aza- $\beta^{3}$-amino acids. ACPP23 contained three adjacent hydrophobic aza- $\beta^{3}$-amino acids (aza- $\beta^{3}-1 \mathrm{Nal} 3$, aza- $\beta^{3}$-Leu 4 and aza- $\beta^{3}-1 \mathrm{Nal} 5$ ) allowing us to investigate the consequence of breaking the $\alpha /$ aza- $\beta^{3}$ amino acids alternation (Figure 1B). For the cationic part, we first chose amine lysyl side chains that were then replaced by arginyl side chains reported to enhance peptide-membrane interactions. ${ }^{[55]}$ Thus, ACPP24 bore two arginyl side chains instead of lysyl side chains among its cationic domain. We also investigated the effect of subtle variations within the hydrophobic moiety by studying the effect of the substitution pattern of the naphthalene ring. We synthesized ACPP21 in which the two aza- $\beta^{3}$-1-naphthylalanine residues were replaced by two aza- $\beta^{3}-2$-naphthylalanine residues with a more elongated shape. ACPP25 was designed by substituting the two leucine residues by two phenylalanine residues and by the replacement of the lysine by an arginine. Finally, ACPP22 was built to inspect the introduction of a sole fluorine on a naphthalene ring because hydrophobic fluorinated $\alpha$-amino acids were known to modulate antimicrobial activities $^{[56,57]}$. Thus, ACPP22 contained an aza- $\beta^{3}-4$-fluoro-1naphthylalanine. Also, the introduction of a fluorine further dispersed the NMR resonances allowing us to disentangle and to fully assign the two naphtylalanine rings chemical shifts in the NMR spectra (vide infra). All these cyclic pseudopeptides were obtained using solid phase peptide synthesis with fluorenylmethyloxycarbonyl (Fmoc)/t-butyl ( $t$-Bu) protection strategy and TBTU/HOBt/DIEA procedure and further cyclized at high dilution in a "head-to-tail" fashion as it was described in our precedent work ${ }^{[51]}$. All the six ACPPs were major products of synthesis with very good yields (38 to $53 \%$, Table 1 ).

All minimal inhibitory concentrations $\left(\mathrm{MIC}_{48 \mathrm{~h}} \mathrm{~s}\right)$ in rich media against 13 bacterial strains (7 Gram-positive and 6 Gramnegative strains) were reported in Table 2 in comparison with the 
highly efficient but also highly cytotoxic natural AMP mellitin as reference. This second generation of ACPPs displayed antibacterial activities on all bacterial species except on the Gramnegative potentially pathogen $A$. caviae, which was also resistant to the mellitin. Aside from this particular case, ACPPs tested in this study exhibited $\mathrm{MIC}_{48 \mathrm{~h}}$ 's below or equal to $100 \mu \mathrm{M}$ on both Gram-positive and Gram-negative strains. They were globally more efficient against Gram-positive strains. First we focused on the biological activity of ACPP20. On Gram-negative bacteria, MICs were comprised between 25 and $50 \mu \mathrm{M}$. This template was particularly potent on Gram-positive bacteria such as $B$. megaterium and $M$. luteus (MICs $=3.12 \mu \mathrm{M}$ ). Interestingly, it also exhibited a good antimicrobial activity against $L$. monocytogenes which is a pathogen found in the contaminated meat (MIC $=12.5$ $\mu \mathrm{M})$. Overall, this cyclic pseudopeptide had almost the same activity profile than the hemolytic mellitin with a slightly lower efficiency threshold. Then, we compared all five other ACPPs to ACPP20 in order to investigate how slight molecular modifications impact the antibacterial activities. First, we noticed that the various substitution pattern of the naphthalene ring had no effect on the antimicrobial activity since ACPP21 displayed the same activity profile. It is noteworthy that the single introduction of a halogen fluorine atom on one naphthalene (ACPP22) decreased the MICs on seven Gram negative and positive strains. Such results may arise since ACPP22 was more hydrophobic than ACPP20 (HPLC retention time of ACPP22 was 25 min instead of $20.6 \mathrm{~min}$ for ACPP20). The activity profile of ACPP23 showed that breaking the alternation of $\alpha$ - and aza- $\beta^{3}$-amino acids had no impact on activities against Gram-positive strains and a very slight effect on Gram-negative ones. Thus, the alternation of $\alpha$ - and aza$\beta^{3}$ residues was not required to maintain the antimicrobial properties of such family of compounds. In contrast, when focusing on the cationic moiety, we could observe that arginyl side chains conferred a notable gain in term of antibacterial activity. Indeed, ACPP24 was more potent against nine of the thirteen tested strains than ACPP20 with significant decreases of the MICs against the Gram positive $L$. garvieae and Gram negative E. coli. Finally, we obtained the most effective ACPP (ACPP25) by replacing apliphatic leucyl side chains by more hydrophobic aromatic phenylalanyl side chains and the incorporation of an $\alpha$ arginine instead of the $\alpha$-lysine. All MICs on Gram-positive bacteria of this hydrophobic ACPP were inferior or equal to 12.5 $\mu \mathrm{M}$. ACPP25 was 4 -fold more effective against $B$. megaterium and $P$. aeruginosa, and 8-fold on $S$. aureus than mellitin.

Then, we determined the hemolytic activities of ACPPs on commercially available sheep erythrocytes to measure their toxicity on mammalian cells (Figure S1). ACPP concentrations causing $50 \%$ hemolysis $\left(\mathrm{HC}_{50}\right)$ and the percentage of hemolysis at $100 \mu \mathrm{M}$ were reported in Table 2. It is noteworthy that the ACPPs analyzed in this study exhibited low hemolytic activities since no $\mathrm{HC}_{50}$ can be calculated in the range of tested concentrations except for ACPP25 that caused $50 \%$ of hemolysis at $100 \mu \mathrm{M}$. Only 1.5 to $12 \%$ of hemolysis were measured in the presence of $100 \mu \mathrm{M}$ ACPP20-24 despite interesting antibacterial profiles. To compare, except ACPP7, the most active compounds of our previous studies exhibited extensive hemolysis, from 55 to $90 \%$ at $100 \mu \mathrm{M} .{ }^{[51]}$ When comparing ACCP20 to the more hemolytic ACPP25 which contained four aromatic residues, it seems that high aromatic content strongly increased the overall antimicrobial activities but also the cytotoxicity on mammalian cells. Indeed, we previously observed similar trends when large biphenylalanyl aromatic moieties were incorporated in the compound ACPP4. ${ }^{[51]}$ We also showed that the moderate increase of the antimicrobial activity was associated to an 8-fold increase of the cytotoxicity when the positively charged lysyl side chains in ACPP20 were simply replaced by arginine side chains to yield ACPP24. Thus, although their antimicrobial activities were slightly lower than the ACPP4 parent pseudopeptide, we successfully widened the set of potent and selective ACPPs.

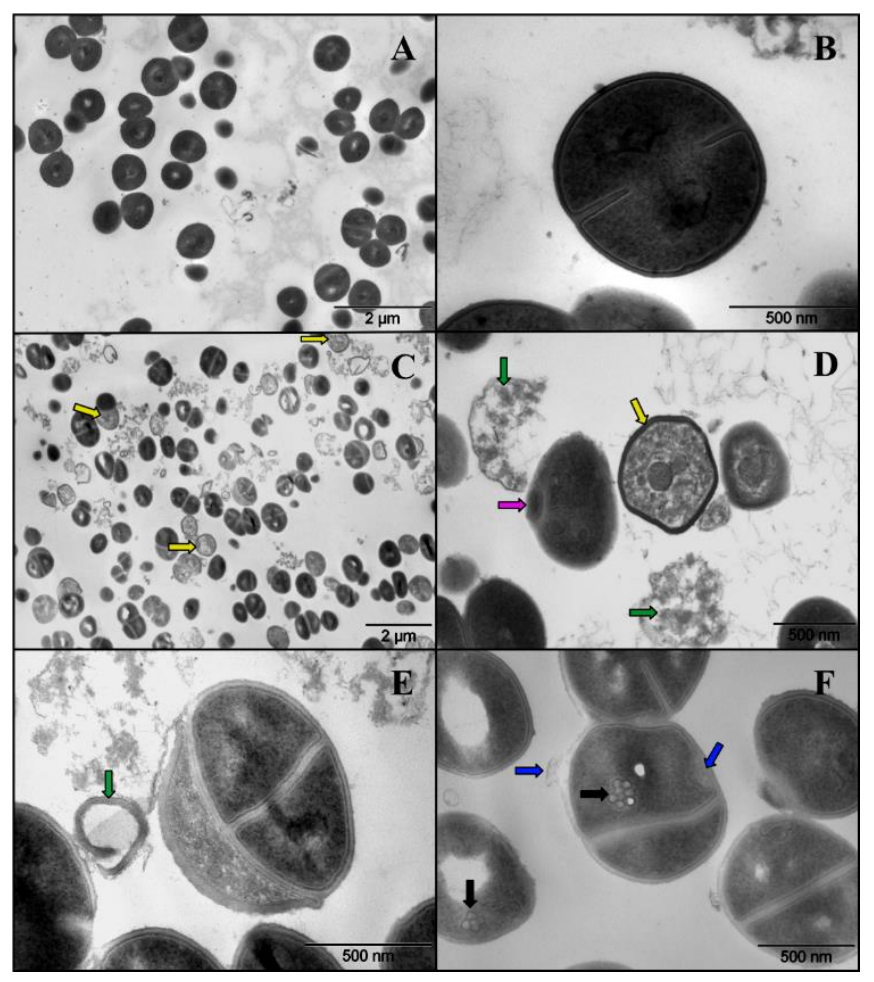

Figure 2. TEM micrographs of $S$. aureus. A) and B) control, C), D), E), and F) treated with $10 \mu \mathrm{M}$ of ACPP20 for $2 \mathrm{~h}$. Yellow arrows point to bacteria with clear intracellular contents, green arrows point to cell debris, blue arrows point to cell wall distortions, pink arrow points to an abnormal vesicular structure, and black arrows point to multivesicular mesosomes.

At this step, these results pointed out the difficulty to develop more potent compounds without impairing their selectivity. In this context, we studied the conformational preference of such family of compounds to consider a structure-based approach to design the next generation of ACPPs. We first investigated the mechanism of action of the potent and less cytotoxic compound ACPP20 recording TEM micrographs. We investigated the effect of ACPP20 on the bacterial cell wall and inspected the bacterial ultrastructural morphology of $S$. aureus after a $2 \mathrm{~h}$ exposure (Figure 2). By comparing control micrographs (Figure 2A-B) and micrographs of $S$. aureus treated by ACPP20 at low magnification for an overall view (Figure $2 \mathrm{~A}$ and $2 \mathrm{C}$ ), we clearly observed a significant alteration of the bacterial morphology in the presence 
of ACPP20. Almost all cells were affected with shapes differing from the homogeneous and dense control bacteria. At a cellular level (Figure 2B and 2D-F), ACPP20 treated cells displayed heterogeneous ultrastructures and electron-dense extracellular components were observed in the media. Such components were absent in control samples. Cell ghosts and section of bacterial membranes were clearly discernible confirming a bactericidal effect of ACPP20. Moreover, all bacteria that were not directly lysed, displayed atypical morphologies while the control cells were symmetrical and well-defined. High magnification micrographs allowed to examine more finely the ultrastructures of treated cells that were not lysed. In addition to cell debris that could correspond to intracytoplasmic components and bacterial cell walls (Figure 2D-E, green arrows), we observed different types of cell modifications upon the action of ACPP20. Some bacteria appeared particularly clear with amorphous intracellular compartments or the cellular contents were entirely leaked (Figure 2C-D, yellow arrows). Other cells had damaged membranes with gaps or deformations (Figure 2F, blue arrows). Cell division that normally occurs according to a perfectly centered axis (Figure 2B) seemed also strongly disturbed. Division axes were randomly positioned and the resulted bacteria had small sizes or were not viable (Figure 2E-F). Finally, we also noticed, vesicular formations (Figure 2D, pink arrows) or multivesicular mesosomes (Figure 2F, black arrows) within the treated cells, that we did not observed in control cells. Such intracytoplasmic mesosomes could be due to membrane rearrangements. These types of TEM micrographs were similar to other micrographs obtained with $S$. aureus cells treated with membrane active antimicrobial peptides such as SMAP29, the gramicidin $S$ and the a-helical peptidyl-glycylleucinecarboxyamide (PGLa). ${ }^{[58,59]}$ All these alterations were consistent with a membrane destabilization induced by a detergent-like mechanism rather than an intracellular target.

The conformational preference of the various compounds was investigated recording $\mathrm{CD}$ spectra in phosphate buffer $(\mathrm{pH} 7.4)$ and in membrane-mimicking media: anionic sodium dodecyl sulfate micelles (SDS) and small unilamellar vesicles (SUVs) of 1-palmitoyl-2-oleoyl-sn-glycero-3-phosphocholine (POPC)/1palmitoyl-2-oleoyl-sn-glycero-3-phospho-L-serine (POPS) 7/3 (Figure 3). We first compared the CD signature of ACPP20 in various media (Figure 3A). In phosphate buffer, ACPP20 exhibited a profile close to the characteristic random coil signature with a large positive maximum around $220 \mathrm{~nm}$. In the presence of SDS micelles or negatively charged liposomes, the CD spectra of ACPP20 shared similar signatures dominated by a strong negative and a positive bands around 221 and $229 \mathrm{~nm}$ respectively, arising from the aromatic moieties of the aza- $\beta^{3}$ naphthylalanine residues. Such typical couplet centered at 225 $\mathrm{nm}$ was attributed to the ${ }^{1} \mathrm{~B}_{\mathrm{b}}$ transition of naphthalene groups which occurred when they were close enough to allow dipoledipole interaction as previously reported. ${ }^{[60,61]}$ This phenomenon was also observed in the presence of anionic micelles for compounds ACPP22, ACPP23 and ACPP24 (Figure 3B). This profile was inverted for ACPP21 and ACPP25 with positive and negative maxima at 221 and $228 \mathrm{~nm}$, respectively (Figure $3 C$ ). Thus, ACPP20, ACPP22, ACPP23 and ACPP24, which incorporated aza- $\beta^{3}-1$-naphthylalanine amino acids displayed mirror CD spectra from those of ACPP21 and ACPP25 containing aza- $\beta^{3}$-2-naphthylalanine amino acids. Nevertheless, such signal inversion seems not directly due to the substitution pattern of the naphthalene rings since previous studies reported both types of $C D$ spectra whatever the position of the anchorage of the alanyl moiety to the naphtalene group. Indeed, similar profiles were recorded for ACPP21, ACCP25 and for the linear antimicrobial pseudopeptides $\mathrm{K}-1 \mathrm{Nal}$ containing two aza- $\beta^{3}$-1-naphthylalanine amino acids or the cyclic antimicrobial hexapeptide RNal containing two $\alpha$-L-naphthylalanine residues in the presence of SDS micelles or SUVs of 1-palmitoyl-2-oleoyl-sn-glycero-3phosphoglycerol (POPG). ${ }^{[51,62]}$ However, the couplet was inverted for the antimicrobial D-peptide D-Nal-Pac-525 incorporating $\beta$-Dnaphthylalanine residues also in the presence of micelles or phospholipids indicating that the type of couplet depended on the configuration of the atoms bearing the naphthylanalyl side chains. ${ }^{[63]}$
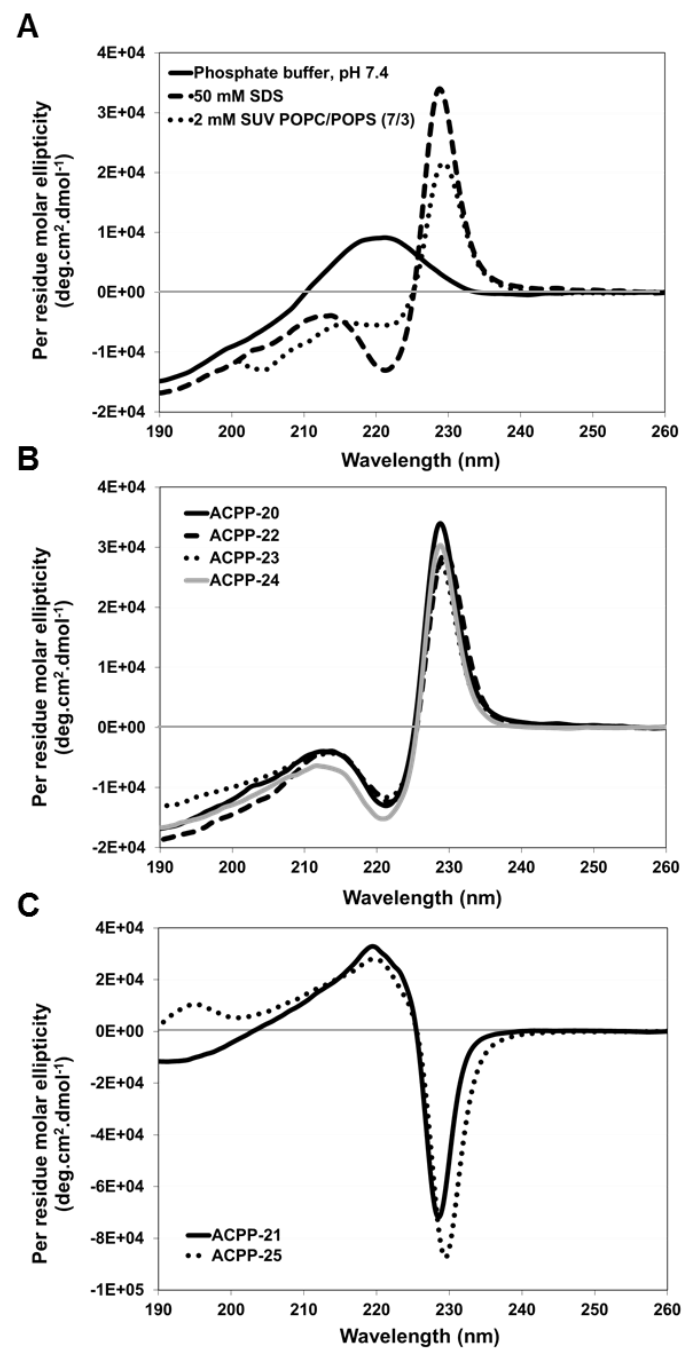

Figure 3. CD spectra of ACPP20-25 at $100 \mu \mathrm{M}$ at $20^{\circ} \mathrm{C}$. A) ACPP20 in various conditions. B) ACPP22, ACPP23 and ACPP24 bearing aza- $\beta^{3}-1-$ naphthylalanine compared to the C) ACPP21 and 25 bearing aza- $\beta^{3}-2$ naphthylalanine in the presence of SDS micelles $(50 \mathrm{mM}), \mathrm{pH} 7.4$. 
Thus, CD spectra of ACPP20, ACPP22, ACPP23 and ACPP24 indicated that the aza- $\beta^{3}-2$-naphthylalanine residues had a $D$ configuration (absolute configuration $\mathrm{R}$ ) while the configuration of the ternary nitrogen of the aza- $\beta^{3}-1$-naphthylalanine amino acids was $L$ (absolute configuration $S$ ) in ACPP21 and ACPP25. We could reasonably conclude that the ACPPs exhibited some degree of an ordered structure with well-defined orientation of the naphthylanalyl side chains when bound to micelles or vesicles. Interestingly, the substitution pattern of the naphthalene ring may influence the stereochemistry of the aza- $\beta^{3}$-naphthylalanine amino acids. The ACPP20, ACPP22, ACPP23 and ACCP24 pseudopeptides had alternations of $L-\alpha-$ and $D$-aza- $\beta^{3}$-amino acids while ACPP21 and ACPP25 were homochiral with L-aza- $\beta^{3}$ amino acids. Despite different stereochemistry pattern, we have seen above that ACPP20 and ACPP21 shared similar antimicrobial profiles while ACPP21 were moderately more cytotoxic. Taking these results altogether, we noticed that the ACPPs antimicrobial profile and cytotoxicity cannot be directly related to their stereochemistry pattern.

To go further, we then focused on the reference compound ACPP20 and its analog ACPP22 containing an aza- $\beta^{3}$-4-fluoro-1naphthylalanine to perform NMR experiments in water, in the presence of micelles and anionic SUVs at pH 5.0. We obtained rather large NMR signals in the presence of SUVs, which hampered the complete assignment of the chemical shifts of ACPP20 and ACPP22, preventing further studies in this media. Thus, we focused on two micellar media, neutral DPC and anionic SDS micelles, to study the impact of the charge of the micelles on the structures of the ACPPs. In contrast to ACPP20, where the signal of the naphthylalanyl rings were strongly overlapped preventing their specific assignment, all the ${ }^{1} \mathrm{H}$ resonances of ACPP22 could be assigned thanks to the fluorine atom bore by the F-Nal 5 side chain (Table S1).
First, we investigated the propensity of ACPP20 to selfassembly when varying the peptide concentration since cyclic D, L-a-peptides can form nanotubular assemblies in water ${ }^{[53]}$. We detected selective proton chemical shift variations associated to slight narrowing linewidths when the ACPP20 concentration decreased (Figure 4), indicating that such compound is able to self-associate. The chemical shifts did not vary further when the peptide concentrations were lower than $1 \mathrm{mM}$ or higher than 12 $\mathrm{mM}$. During the titration, the spectra remained well-resolved with narrow linewidths at high concentrations indicating that the ACPP20 complex was composed of only a few units and/or was highly dynamic. The exchange between the monomeric and the associate states of ACPP20 is fast on the chemical shift timescale and the complex had a weak affinity since the transition between the two states was around $7 \mathrm{mM}$. Such behavior was confirmed by dynamic light scattering (DLS) and NMR diffusion experiments. When ACPP20 was dissolved at $10 \mathrm{mM}$, we observed two populations with hydrodynamic radii of $1 \pm 0.2 \mathrm{~nm}$ and $3.1 \pm 0.9$ $\mathrm{nm}$ and apparent diffusion translational coefficient values of 2.9 and $1.2 \times 10^{-10} \mathrm{~m}^{2} . \mathrm{s}^{-1}$, corresponding to the monomeric and the oligomeric species, respectively (Figure S2 and S3). Considering the non-spherical shape of ACPP20, it was rather difficult to accurately estimate the number of units that composed the ACPP20 complex. Two or three molecules of ACPP20 could interact together or they could form small compact pseudopeptide amphiphile micelles as previously reported ${ }^{[64]}$. In this context, we were then interested in identifying the interface between the ACPP20 molecules monitoring the chemical shift variations upon the formation of the complex. Interestingly, we noticed that not all the chemical shifts were affected by the self-assembly process but more particularly the resonances of the hydrophobic moiety (Figure 4A).
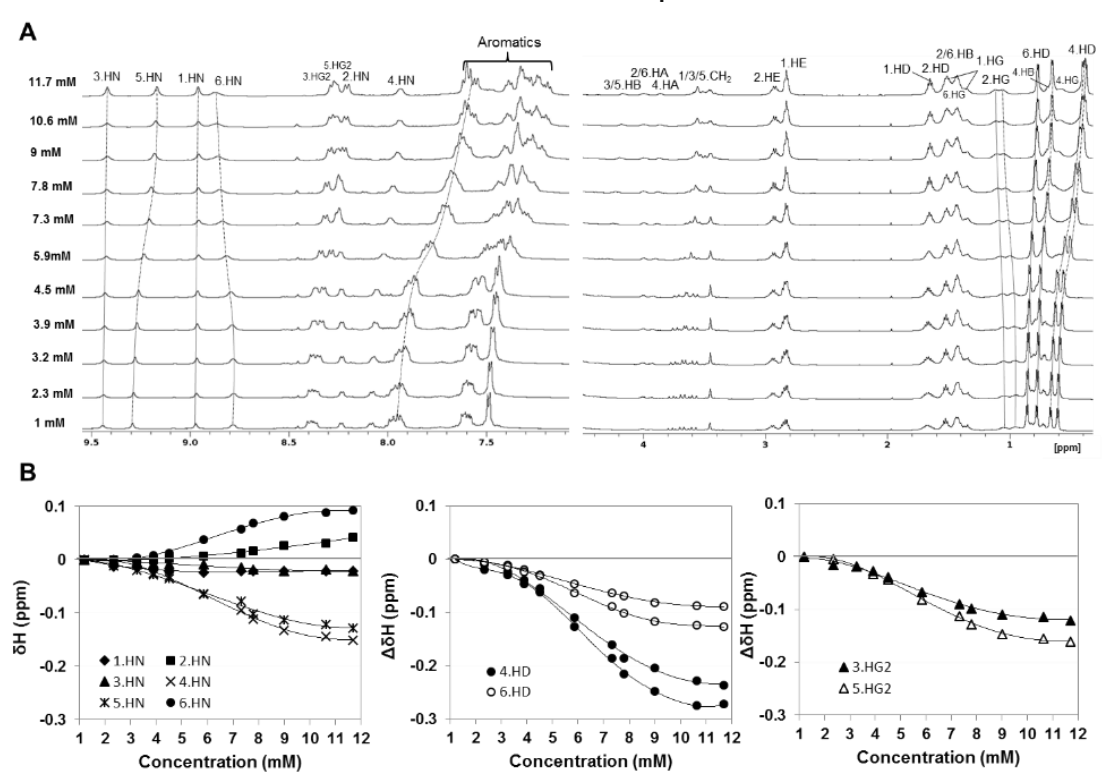

Figure 4. Monitoring of the ACPP20 self-assembly by NMR. A) ${ }^{1} \mathrm{H}$ NMR spectra of ACPP20 at various concentrations (from 1 to $12 \mathrm{mM}$ ) in $\mathrm{H}_{2} \mathrm{O} / \mathrm{D}_{2} \mathrm{O}(9: 1)$, $\mathrm{pH} 5$ at $293 \mathrm{~K}$. B) Variations of the ACPP20 protons chemical shifts with the concentration (from 1 to $12 \mathrm{mM}$ ): Amine protons (left), methyl groups (HD) of the leucine residues (middle) and aromatic protons (HG2) of the naphtylalanine residues (right). 
The chemical shifts of the lysyl methylene groups did not changed markedly while the protons of the leucine and naphthylalanine side chains were shielded upon the formation of the ACPP20 complex. Similarly, most of the ACPP22 hydrophobic side chain proton resonances were strongly shielded, except Leu 6, while few chemical shift perturbations were observed for the charged moiety. Such results showed that the interface between the monomers mainly involved the side chains of the two naphthylalanine residues 3 and 5 and the intercalated leucine residue 4 (Figure S4A, S4D). Then, we finely investigated the interaction of ACPP22 with DPC and SDS micelles (Figure S4B$C)$. The fluorine atom of the aza- $\beta^{3}-4$-fluoro-1-naphthylalanine residue induced a high dispersion of the ${ }^{1} \mathrm{H}$ resonances of the aromatic naphtylalanine protons over $1.1 \mathrm{ppm}$ versus $0.5 \mathrm{ppm}$ for ACPP20, allowing their complete assignment. When DPC or SDS micelles were added to $1 \mathrm{mM}$ of ACPP22, chemical shift variations differed significantly from those observed when varying the peptide concentration. However, the presence of neutral or negative micelles induced rather comparable ${ }^{1} \mathrm{H}$ resonance perturbations with globally similar trends (Figure S4B-D). Thus, we can reasonably hypothesize that the presence of micelles should prevent the formation of the ACPP22 complex. Also, ACPP22 should display similar conformational preference whatever the type of micelles. A detailed analysis of the chemical shift perturbations in the various conditions are presented in supplemental data (Figure S4).

Thus, we then sought information on the conformational preference of ACPP22 in a monomeric form, in complex and in the presence of DPC and SDS micelles analyzing the NOE correlations at different concentrations and in various media. First, only few NOEs were detected on the ROESY or NOESY spectra of ACPP22 at $1 \mathrm{mM}$ indicating that such compound was disordered as monomer in water according to its $C D$ random coil signature. In contrast, numerous negative NOEs cross-peaks were detected for the ACPP22 complex (at $12 \mathrm{mM}$ ) according to a higher molecular weight. We failed to discriminate the intra- from the inter-molecular NOE correlations in such small homooligomeric systems and we could not calculate any threedimensional structure of this complex. In contrast, we gathered consistent sets of NOEs, which were similar in the presence of both neutral DPC and cationic SDS micelles. We observed weak $\mathrm{HN}(\mathrm{i}) / \mathrm{HN}(\mathrm{i}+1)$, two medium and stereospecific $\mathrm{HN}(\mathrm{i}) / \mathrm{HS}(\mathrm{i}-1)$, and strong $\mathrm{HN}(\mathrm{i}) / \mathrm{HA}(\mathrm{i}-1) \quad \mathrm{NOE}$ correlations all along the pseudopeptide cycle (Figure 5A). Moreover, we detected unambiguous characteristic medium $\mathrm{HZ2}(\mathrm{i})-\mathrm{HG}(\mathrm{i}+1)$ correlations involving the naphthylalanyl moieties and the next leucine side chains, and weak $\mathrm{HZ2}(\mathrm{i})-\mathrm{HN}(\mathrm{i}+1)$ and $\mathrm{HNi}-\mathrm{HN}(\mathrm{i}+1)$ cross-peaks involving the amide protons. No correlation involving the lysyl side chains within the cationic part were found on the NOESY spectra of ACPP22. The ACPP22 structures were calculated using 142 and 105 distance restraints in the presence of SDS and DPC micelles, respectively. For each calculations, we selected the 20 lowest energy conformers with no distance violations $>0.3 \AA$ (Figure $5 B$ ). Close structures were obtained in both media, RMSD on the heavy atoms was $0.571 \AA$ and $0.488 \AA$ and fall to $0.086 \AA$ and $0.085 \AA$ when the side chains were omitted, in SDS and DPC micelles respectively (Table S3, Figure S5).

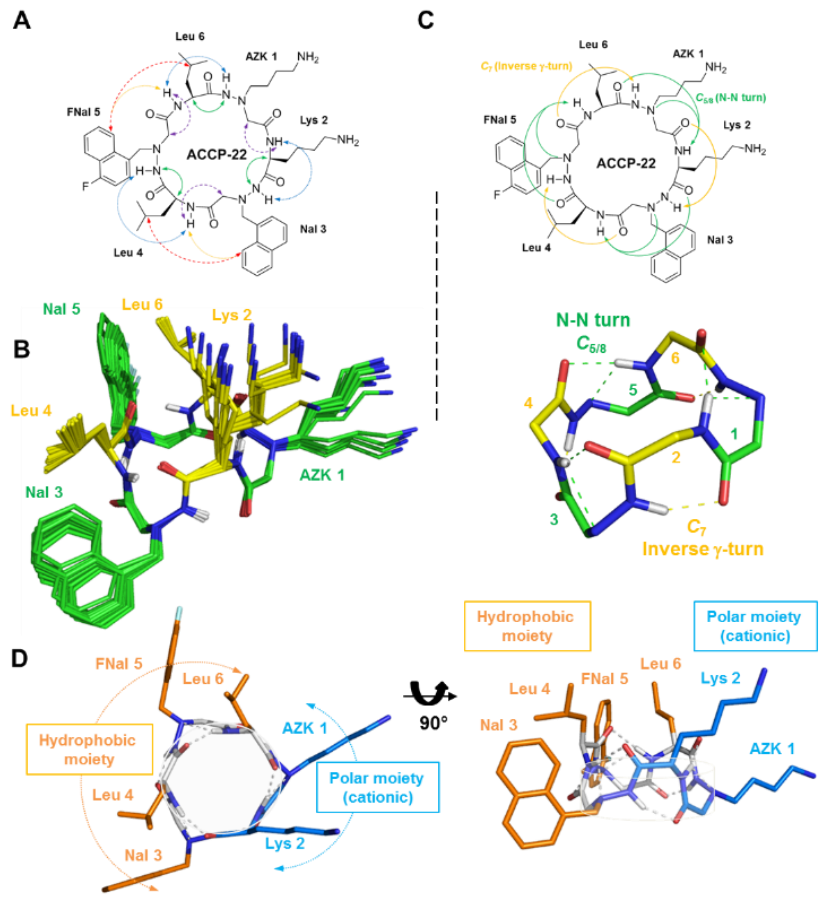

Figure 5. Structure of ACPP22 in SDS micelles. A) Characteristic inter-residue NOE correlations. $\mathrm{HN}(\mathrm{i}) / \mathrm{HN}(\mathrm{i}+1), \mathrm{HN}(\mathrm{i}) / \mathrm{H} \alpha(\mathrm{i}-1), \mathrm{HN}(\mathrm{i}) / \mathrm{HS}(\mathrm{i}-1), \mathrm{HG} 2(\mathrm{i}) / \mathrm{HN}(\mathrm{i}+1)$ and $H G 2(i) / H G(i+1)$ are in blue, green, purple, orange and red, respectively. 'Strong' $(\mathrm{d}<2.7 \AA)$, 'medium' $(\mathrm{d}<3.3 \AA)$ and 'weak' $(\mathrm{d}<5 \AA)$ correlations are indicated as plain, dashed and dotted arrows, respectively. B) Superimposition of the heavy atoms of the backbone of the 20 lowest energy NMR solution structures. $\alpha$ - and aza- $\beta^{3}$-amino acids are in yellow and green, respectively. C) Typical hydrogen-bond pattern of ACPP22. Hydrogen bonds forming the $C_{7}$ and $\mathrm{C}_{5 / 8}$ pseudocycles stabilizing the inverse $\gamma$ - and $\mathrm{N}-\mathrm{N}$ turns are indicated as yellow and green arrows (top) and dashed lines (bottom), respectively. D) Distribution of the hydrophobic (orange) and cationic (blue) moieties around the ACPP22 cyclic backbone.

The cyclic backbone alternating $\alpha$ - and aza- $\beta^{3}$-amino acids exhibited successive inverse $\gamma$-turns stabilized by $\mathrm{CO}(\mathrm{i}) \cdots \mathrm{HN}(\mathrm{i}+2)$ hydrogen bonds and R-hydrazinoturns (or N-N turns) where the amide proton of the residue i was hydrogen-bonded with both the lone pair of the $\mathrm{sp}^{3}$ nitrogen atom of the residue (i-1) and the carbonyl of the residue (i-2) (Figure $5 \mathrm{C}$ ). The typical average dihedral angles values were $\phi=-78 \pm 3^{\circ}$ and $\psi=56 \pm 5^{\circ}$ for the $\alpha$-amino acids, and $\phi=119 \pm 2^{\circ}, \theta=-75 \pm 3^{\circ}$ and $\psi=3 \pm 5^{\circ}$ for the aza- $\beta^{3}$ residues in micelles. The aza- $\beta^{3}$-amino acids absolute configuration was $R$ in good agreement with the sign of the couplet on the CD spectra. Thus, the ternary nitrogen configuration of the aza- $\beta^{3}$-amino acids in hybrid cyclic $L$ - $\alpha / a z a-$ $\beta^{3}$-peptides was fixed similarly within previously reported cyclic aza- $\beta^{3}$-peptides incorporating a single (S)- $\beta^{3}$-homo-amino acids. ${ }^{[42]}$ Nevertheless, such feature was also due to the conformational restraint induced by the peptide cyclization since we previously showed that the configuration of the ternary nitrogen was nonfixed in linear peptides including aza- $\beta^{3}$-amino acids. ${ }^{[50]}$ The alternation of inverse $\gamma$ - and $\mathrm{N}-\mathrm{N}$ turns oriented the $\alpha$-amino acid side chains together on the same side of the cyclic backbone (axial orientation) while the aza- $\beta^{3}$-residue side chains 
were projected around the cycle (equatorial orientation) (Figure $5 \mathrm{D})$. The hydrophobic side chains of aza- $\beta^{3}-1 \mathrm{Nal} 3$ and aza- $\beta^{3}-$ $1 \mathrm{Nal} 5$ were close to the Leu 4 and Leu 6 isopropyl groups, respectively, while the AZK 1 and Lys 2 amine groups were projected toward the other side of the cyclic backbone (Figure 5D). The hydrophobic moiety displayed a similar highly organized cluster in the presence of neutral or anionic micelles while the cationic side chains remained disordered. We noticed that the MICs and the hemolytic activity of ACPP22 were comparable to those of ACPP23 of which the $\alpha /$ aza- $\beta 3$-amino acids alternation was punctually altered by the substitution of a $\alpha$-amino acid by its aza- $\beta^{3}$ analog. Such result indicated that the successive inverse $\gamma$ - and $\mathrm{N}-\mathrm{N}$ turns over the entire pseudopeptide backbone was not mandatory for this family of compounds to exhibit antimicrobial activity. Nevertheless, the naphthylanalyl side chains may be similarly oriented within ACPP23 and ACPP22 according to their comparable $C D$ profile. Considering their detergent-like mechanism of action, their amphipathic sequences with an appropriate aromatic content and number of charges were major parameters to develop efficient compounds. Such compounds were able to self-assemble but at rather high concentrations. While the relationship between the three-dimensional structure and the activity of the ACPPs remained ambiguous, the knowledge of the spatial distribution of the ACPP side chains will help us to develop a new generation of structure-based amphipathic compounds.

\section{Conclusions}

We previously established general rules to design active and protease-resistant antimicrobial pseudopeptides incorporating aza- $\beta^{3}$-amino acids (six membered cycles, two positive charges, non-proteinogenic side chains). Nevertheless, the development of potent but also selective compounds was highly challenging and the three-dimensional structure and detailed mechanism of action of such family of compounds remained unknown. In this context, we reported, here, potent but also selective hybrid cyclic pseudopeptides mixing $\alpha$ - and aza- $\beta^{3}$-amino acids against a broad range of Gram-positive and Gram-negative bacteria. The number of aromatic side chains but also the precise nature of the aromatic moieties was crucial for the selectivity of our family of compounds. Indeed, very close sequences ranged from $50 \%$ to only $1.5 \%$ of hemolysis at $100 \mu \mathrm{M}$ concentration while remaining highly antibacterial. Thus, we noticed that only subtle side chain modulations led to strong variations of the pseudopeptides cytolytic activity. In this context, we carried out structural investigations to describe the spatial distribution of the various side chains in $\alpha /$ aza- $\beta^{3}$-cyclopseudopeptides. The latter adopted a unique structure composed of successive inverse $\gamma$ - and N-N turns in micellar media. Such organization projected the $\alpha$-amino acid side chains together on the same face of the pseudopeptide cycle while the aza- $\beta^{3}$-amino acid side chains were dispersed around the cyclic backbone on the cycle plane. Such data are of great importance to rationally design the next generation of ACPPs incorporating aza- $\beta^{3}$-amino acids or to consider further applications.

\section{Experimental Section}

Automated Solid-Phase Synthesis of Mixed Aza- $\beta^{3}$-Pseudopeptides Linear pseudopeptides were synthesized on a Pioneer Peptide Synthesis System ${ }^{\circledR}$ with standard Fmoc solid phase peptide synthesis protocol. The synthesis was performed using commercially available $N^{a}$-Fmoc-amino acid, $N^{\beta}$-Fmoc-aza- $\beta^{3}$-amino acid ${ }^{[43-46]}$ and 2-chlorotrityl chloride resin. Typically, 2-chlorotrityl chloride resin (100-200 mesh; $1.2 \mathrm{mmol} / \mathrm{g}, 1 \mathrm{~g})$ was swelled in dry dichloromethane $(\mathrm{DCM})(10 \mathrm{~mL})$ for $10 \mathrm{~min}$. The first monomer was attached onto the resin by adding a solution of $N^{\alpha}$-Fmocamino acid or $N^{\beta}$-Fmoc-aza- $\beta^{3}$-amino acid (1.2 eq.) in dry DCM $(10 \mathrm{~mL})$ and diisopropylethylamine (DIPEA) (4 eq.) on a shaker platform for $4 \mathrm{~h}$ at room temperature under nitrogen atmosphere. The loading resin was washed with dimethylformamide (DMF) $(5 \times 10 \mathrm{~mL})$, dry DCM $(3 \times 10 \mathrm{~mL})$, then with a mixture of DCM/MeOH/DIPEA $(17 / 2 / 1)(2 \times 10 \mathrm{~mL})$ and finally with DMF $(3 \times 10 \mathrm{~mL})$. The yield of the loading step was determined on the absorption of dibenzofulvene-piperidine adduct $\left(\lambda_{\max }=301 \mathrm{~nm}\right)$. Pseudopeptides were synthesized via Fmoc solid phase synthesis methods using a 4 -fold excess of amino acid, 2(-1H-benzotriazole-1-yl)1,1,3,3-tetramethylaminium tetrafluoroborate (TBTU), and 1-hydroxybenzotriazole $(\mathrm{HOBt})$ in the presence of an 8-fold excess of DIPEA for $1 \mathrm{~h}$ for standard residues and $2 \mathrm{~h}$ for aza- $\beta^{3}$ residues. The Fmoc group was removed with $20 \%$ piperidine in DMF for $10 \mathrm{~min}$. At the end of the synthesis, the resin was washed with DCM, dried and then treated with a solution of $3 \%$ trifluoro acetic acid (TFA) in DCM $(30 \mathrm{~mL})$ for $20 \mathrm{~min}$ at room temperature. The resin slurries were then filtered. The cleavage solution was neutralized with a solution of $\mathrm{N}$-methyl morpholine, concentrated in vacuo and the resulting oil was dissolved in DCM $(170 \mathrm{~mL})$. The linear pseudopeptides were slowly added to a solution of 1-ethyl-3-(3'dimethylaminopropyl) carbodimide (EDC), $\mathrm{HOBt}$ (4 equiv) and diisopropylethylamine DIPEA (4 equiv) in DCM (to a final concentration of $10^{-4} \mathrm{M}$ ). The resulting mixture was stirred for 2 days. The crude mixture was concentrated in vacuo. The resulting oily residue was dissolved in DCM and washed with $0.5 \mathrm{M} \mathrm{HCl}$, water, and saturated sodium chloride. The organic phases were dried under sodium sulfate and then concentrated. Side chain deprotection was performed by treatment with TFA $/ \mathrm{H}_{2} \mathrm{O} /$ triisopropylsilane (TIS) $(95 / 2.5 / 2.5, \mathrm{v} / \mathrm{v} / \mathrm{v})$ for $3 \mathrm{~h}$. The TFA solution was concentrated in vacuo and pseudopeptide was precipitated by addition of cold diethyl ether. Pseudopeptides were purified by RPHPLC on a C18 XTerra ${ }^{\circledR}$ semi-preparative column $(10 \mu \mathrm{m}, 19 \mathrm{~mm} \times 300$ $\mathrm{mm}$, Waters) with a linear gradient of water, $0.08 \%$ TFA (A) /acetonitrile, $1 \%$ TFA (B) $(5-60 \%$ B in $40 \mathrm{~min}$ and $60-100 \%$ B in $20 \mathrm{~min}, 8 \mathrm{~mL} / \mathrm{min}, 215$ $\mathrm{nm}$ ) to a final purity of $\geq 95 \%$ and lyophilized. Characterization of purified pseudopeptides by RP-HPLC analyses was performed on a C18 XTerra ${ }^{\circledR}$ $(4.6 \times 250 \mathrm{~mm}, 5 \mu \mathrm{m})$ column using water $0.08 \%$ TFA (A) / acetonitrile, $1 \%$ TFA (B) linear gradient (5-60\% B in $\left.20 \mathrm{~min}, 1 \mathrm{~mL} / \mathrm{min}, 30^{\circ} \mathrm{C}, 215 \mathrm{~nm}\right)$. Pseudopeptide concentrations for all experiments were calculated as the TFA salt (assuming association of one molecule of TFA per cationic residue, determined by ${ }^{13} \mathrm{C}$ NMR). The analytical laboratory from the Centre Régional de Mesures Physiques de l'Ouest performed electrospray mass spectrometry (HR-MS, ESI) studies using MS/MS Mass spectrometer ZAB Spec TOF.

Antibacterial Assays in Rich Medium. The microtiter broth dilution method used to assess antimicrobial potency of ACPPs in this study is based on the Clinical and Laboratory Standards Institute (CLSI) guidelines. ${ }^{[65]}$ This method was only slightly modified. Indeed, assay volumes were increased to $200 \mu \mathrm{L}$ to improve reproducibility. Incubation time from 16 to $20 \mathrm{~h}$ was extended to $48 \mathrm{~h}$ since growth delay was observed leading to MIC underestimation. MIC values were determined by optical density (OD) at $600 \mathrm{~nm}$ to confirm unaided-eye observations (determined by a lack of turbidity). Briefly, MICs of pseudopeptides were measured by liquid growth inhibition assay, performed in sterile 96-well microtiter plates (Nunc). Microbial growth was assessed after $48 \mathrm{~h}$ 
incubation in Tryptone Soy Broth (TSB), agar $16 \mathrm{~g} / \mathrm{L}, \mathrm{pH} 7.4$ (Biokar Diagnostics, Beauvais, France) at the optimal growth temperature depending on the strain. The bacterial strains tested were Gram-positive Bacillus megaterium (American Type Culture Collection ATCC 10778), Enterococcus faecalis (Collection of "Institut Pasteur" CIP A186), Listeria monocytogenes (SOR 100, a strain isolated from food meat product), Streptococcus equinus (ATCC 5623), Micrococcus luteus (ATCC 10 240), Lactococcus garviae (ATCC 43921), Staphylococcus aureus (ATCC 25923); and Gram-negative Escherichia coli (ATCC 25922), Salmonella enterica (ATCC 13076), Pseudomonas aeruginosa (ATCC 27853), Klebsiella oxytoca (CIP 7932), Enterobacter aerogenes (ATCC 13048), Aeromonas caviae (ATCC 15468). All bacteria were grown at $37^{\circ} \mathrm{C}$ except Bacillus megaterium, Lactococcus garviae, and Aeromonas caviae, which were incubated at $25^{\circ} \mathrm{C}$. Bacteria from a single colony were grown overnight in TSB at the optimal growth temperature under shaking. An aliquot was diluted in fresh broth and cultured up to an exponential growing phase. Bacteria were collected and inoculated at $2 \times 10^{5} \mathrm{CFU} / \mathrm{mL}$ in TSB 2X. A 2-fold serial dilution of pseudopeptide in sterile distillated water was then added. After $48 \mathrm{~h}$ incubation at the optimal growth temperature of the target cells, bacterial growth was measured at $600 \mathrm{~nm}$ for optical density. Determination was carried out in triplicate. MIC was defined as the lowest pseudopeptide concentration displaying $100 \%$ growth inhibition after $48 \mathrm{~h}$ of incubation. The MICs of the well-known antimicrobial peptide melittin were also determined as control.

Hemolytic Activity. The hemolytic activity of analogs was determined with commercially available sheep erythrocytes (sRBCs) (Sigma). Erythrocytes were washed by centrifugation with saline phosphate buffer (PBS 1X, pH 7.4) at $900 \mathrm{~g}$ for $5 \mathrm{~min}$ until the supernatant was clear. The sRBCs were resuspended and diluted with PBS to a final concentration corresponding to OD $540 \mathrm{~nm} 0.8$ for the $100 \%$ hemolysis control well ( $1 \%$ Triton X-100). Twofold serial dilution of pseudopeptides in PBS in a 96-well plate resulted in a final volume of $100 \mu \mathrm{L}$ per well, in which $100 \mu \mathrm{L}$ of sRBCs were added. Plates were incubated for $1 \mathrm{~h}$ at $37^{\circ} \mathrm{C}$, followed by centrifugation at $500 \mathrm{~g}$ for 5 min using a tabletop centrifuge. Supernatants were collected and hemolysis was determined by measuring the optical density of the supernatant at $540 \mathrm{~nm}$. Zero hemolysis (blank) and 100\% hemolysis were determined with PBS buffer alone and PBS containing $1 \%$ Triton X-100, respectively. Percentage of hemolysis was calculated using the following equation:

$\%$ of hemolysis $=100 \times\left[\left(A_{540 \text { pseudopeptide }}-A_{540 \text { blank }}\right) /\left(A_{540 \text { tritonx-100 }}-A_{540}\right.\right.$ blank)]

For each concentration and control, the experiments were set in triplicate.

Transmission Electron Microscopy. Using TEM, we could visualize bacterial ultrastructures, and therefore how ACPPs affected bacterial cellular integrity. Here, we choose to investigate how ACPPs affected a $S$. aureus strain in Poor-Broth liquid medium (PB: $1 \%$ peptone, $0.5 \% \mathrm{NaCl}$, $\mathrm{w} / \mathrm{v}, \mathrm{pH}$ 7.5). Briefly, a mid-logarithmic phase culture of $S$. aureus ATCC $6538 \mathrm{P}\left(\mathrm{OD}_{600}=0.6\right.$ ) was in duplicate exposed to $10 \mu \mathrm{M}$ of ACPP20 (MICPB $\times 2$ ) or to water as a control in PB for $2 \mathrm{~h}$ at $37^{\circ} \mathrm{C}$. Bacteria were pelleted by centrifugation at $3000 \mathrm{~g}$ for $5 \mathrm{~min}$ and washed twice in PBS, at $\mathrm{pH} 7.4$. The cells were then fixed and processed for TEM. Stages of sample preparation (fixation, post-fixation, dehydration, resin inclusion and cuts) were made by Dr. Didier Roux, research engineer at the Center for Applied Microscopy in Biology (CMABio) at the University of Caen.

Circular Dichroism. CD experiments were carried out using a JASCO J815 spectropolarimeter (Easton, USA) equipped with Peltier device for temperature control. All spectra were recorded with a quartz cell of $2 \mathrm{~mm}$ path length. Spectra were recorded at a peptide concentration of $100 \mu \mathrm{M}$ in different environments: phosphate buffer $(10 \mathrm{mM})$ at $\mathrm{pH} 7.4$, in the presence of sodium dodecyl sulfate (SDS) detergent $(50 \mathrm{mM})$ and SUVs of 1-palmitoyl-2-oleoyl-sn-glycero-3-phosphocholine (POPC)/1-palmitoyl2-oleoyl-sn-glycero-3-phospho-L-serine (POPS) 7/3 (2 mM, Avanti Polar Lipids). The baseline-corrected spectra were smoothed, ellipticities were converted to mean residue molar ellipticities in degree. $\mathrm{cm}^{2} . \mathrm{dmol}^{-1}$.

Dynamic Light Scattering. Dynamic light scattering (DLS) experiments were performed at $20^{\circ} \mathrm{C}$ on a Malvern 4800 PCS equipped with an Ar laser $(488 \mathrm{~nm})$ at pH 5. ACPP20 samples were prepared at $10 \mathrm{mM}$ and were passed through a $0.2 \mu \mathrm{m}$, Whatman nanodisc filter before any measurement. The data was analyzed to obtain the hydrodynamic radius $(R H)$ values for each sample. Approximately 100 measurements were collected for each of three independently prepared samples.

NMR Experiments. The NMR samples contained $1 \mathrm{mM}$ of ACPP20 or ACPP22 dissolved in aqueous $\left(\mathrm{H}_{2} \mathrm{O} / \mathrm{D}_{2} \mathrm{O}, 9: 1\right)$ or micellar solutions of 50 mM SDS $d-25$ or dodecylphosphocholine (DPC) $d-38$ (Euriso-top) or in the presence of $50 \mathrm{mM}$ SUVs of 1,2-dioleoyl-sn-glycero-3-phosphocholine (DOPC)/1,2-dioleoyl-sn-glycero-3-phospho-L-serine (DOPS) (7/3) (Avanti Polar Lipids). The $\mathrm{pH}$ was adjusted to 5.0. Variations in chemical shifts and line width narrowing could be observed up to $50 \mathrm{mM}$ SDS, DPC and SUVs then no change occurred at higher concentrations for both peptides. Thus, the concentrations of detergent and SUVs were subsequently set at 50 $\mathrm{mM}$ for the further experiments. Experiments at variable concentrations were conducted from 12 to $1 \mathrm{mM}$ of ACPP20 in $\mathrm{H}_{2} \mathrm{O}_{/} \mathrm{D}_{2} \mathrm{O}(9: 1)$ at $\mathrm{pH} 5.0$, $\mathrm{T}=293 \mathrm{~K}$. Pulsed-field gradient spin-echo NMR (PGSE-NMR) method ${ }^{[66}$ was used as previously reported ${ }^{[67]}$ to measure its self-diffusion at 2 and $20 \mathrm{mM}$. NMR signals give rise to exponential decays in the diffusion spectra, and the apparent translational diffusion coefficients were obtained with Topspin (Bruker Biospin) by fitting the following equation to the NMR data:

$$
\ln \frac{I}{I_{0}}=-D \gamma^{2} g^{2} \delta^{2}\left(\Delta-\frac{\delta}{3}\right)
$$

with $\mathrm{I}$ and $\mathrm{I}_{0}$ representing the measured and maximum intensities, respectively, $D$ the translational diffusion coefficient, $y$ the ${ }^{1} \mathrm{H}$ gyromagnetic ratio, $g$ the gradient strength, $\delta$ the pulsed-field gradient duration and $\Delta$ the diffusion delay time ${ }^{[68]}$. The gradient strength was varied from 0.09 to 0.45 $\mathrm{Tm}^{-1}$ in 16 steps, $\delta$ was set to $6 \mathrm{~ms}$ and $\Delta$ values were 50 and $100 \mathrm{~ms}$, for the monomeric and associated forms, respectively. The ACPP20 selfdiffusion coefficients were obtained by calculating the mean values between coefficients measured from two groups of aliphatic resonances (Figure S3).

All spectra were recorded on a Bruker Avance 500 spectrometer equipped with a $5 \mathrm{~mm}$ triple-resonance cryoprobe $\left({ }^{1} \mathrm{H},{ }^{13} \mathrm{C},{ }^{15} \mathrm{~N}\right)$. Homonuclear 2-D spectra DQF-COSY, TOCSY (MLEV) and NOESY were recorded in the phase-sensitive mode using the States-TPPI method as data matrices of 256 real $\left(\mathrm{t}_{1}\right) \times 2048\left(\mathrm{t}_{2}\right)$ complex data points; 64 scans per $\mathrm{t}_{1}$ increment with $1.5 \mathrm{~s}$ recovery delay and spectral width of $5341 \mathrm{~Hz}$ in both dimensions were used. The mixing times were $100 \mathrm{~ms}$ for TOCSY and $200 \mathrm{~ms}$ for the NOESY experiments. In addition, 2D heteronuclear spectra ${ }^{13} \mathrm{C}-\mathrm{HSQC}$ and ${ }^{13} \mathrm{C}-\mathrm{HMBC}$ were acquired to help to fully assign the naphthylalanyl side chains. Spectra were processed with Topspin (Bruker Biospin) and visualized with Topspin or NMRview ${ }^{[69]}$ on a Linux station. The matrices were zero-filled to $1024\left(\mathrm{t}_{1}\right) \times 2048\left(\mathrm{t}_{2}\right)$ points after apodization by shifted sine-square multiplication and linear prediction in the F1 domain. Chemical shifts were referenced to the trimethylsilylpropanoic acid- $d_{4}$ (TMSP- $\left.d_{4}\right)$.

Structure Calculations. ${ }^{1} \mathrm{H},{ }^{15} \mathrm{~N}$ and ${ }^{13} \mathrm{C}$ chemical shifts were assigned according to classical procedures. NOE cross-peaks were integrated and assigned within the NMRView software. The volumes of NOE peaks between methylene pair protons were used as reference of $1.8 \AA$. The 
lower bound for all restraints was fixed at $1.8 \AA$ and upper bounds at 2.7 , 3.3 and $5.0 \AA$, for strong, medium and weak correlations, respectively. Pseudo-atoms corrections of the upper bounds were applied for unresolved aromatic, methylene and methyl protons signals as described. ${ }^{[70]}$ Structure calculations were performed with AMBER $16^{[71]}$ in two stages: cooking, simulated annealing using the generalized Born (GB) implicit solvent model. The cooking stage was performed at $1000 \mathrm{~K}$ to generate 100 initial random structures. SA calculations were performed during 20 ps (20000 steps, 1 fs long). First, the temperature was risen quickly and maintained at $1000 \mathrm{~K}$ for the first 5000 steps, then the system was gradually cooled from $1000 \mathrm{~K}$ to $100 \mathrm{~K}$ from step 5001 to 18000 and finally the temperature was brought to $0 \mathrm{~K}$ during the 2000 remaining steps. For the 3000 first steps, the force constant of the distance restraints was increased gradually from $2.0 \mathrm{kcal} . \mathrm{mol}^{-1} \AA$ to $20 \mathrm{kcal} . \mathrm{mol}^{-1} . \AA$. For the rest of the simulation (step 3001 to 20000), the force constant is kept at 20 $\mathrm{kcal} . \mathrm{mol}^{-1} . \AA$. The 20 lowest energy structures with no violations $>0.3 \AA$ were considered as representative of the compound structure. The representation and quantitative analysis were carried out using MOLMOL ${ }^{[72]}$ and PyMOL (Delano Scientific).

\section{Acknowledgements}

We thank SERB Laboratories and Region Bretagne for their financial support. We thank Pr. F. Vovelle, Dr. Eduardo Basilio de Oliveira, Dr. Céline Zatylny-Gaudin, Didier Gerart and Marc Tamisier for their contributions to this study, and Dr. Audrey Guesdon for post-editing the manuscript. We are most grateful to the PRISM core facility (Rennes, France) for the NMR and the Spectroscopy platform (Biosit, Rennes, France) for the circular dichroism facilities.

Keywords: aza- $\beta^{3}$-amino acid, aza- $\beta^{3}$-peptides, peptidomimetics, cyclic peptides, antibiotics, antibacterial, antimicrobial agents.

[1] WHO, "Critically important antimicrobials for human medicine 5th revision," 2017.

[2] I. M. Gould, Int. J. Antimicrob. Agents 2009, 34, S2-S5.

[3] H. W. Boucher, G. H. Talbot, J. S. Bradley, J. E. Edwards, D. Gilbert, L. B. Rice, M. Scheld, B. Spellberg, J. Bartlett, Clin. Infect. Dis. Off. Publ. Infect. Dis. Soc. Am. 2009, 48, 1-12.

[4] D. J. Payne, M. N. Gwynn, D. J. Holmes, D. L. Pompliano, Nat. Rev. Drug Discov. 2007, 6, 29-40.

[5] J. G. Hurdle, A. J. O'Neill, I. Chopra, R. E. Lee, Nat. Rev. Microbiol. 2011, 9, 62-75

[6] M. Zasloff, Nature 2002, 415, 389-395.

[7] K. A. Brogden, Nat. Rev. Microbiol. 2005, 3, 238-250.

[8] R. E. W. Hancock, H.-G. Sahl, Nat. Biotechnol. 2006, 24, 1551-1557.

[9] H. G. Boman, Annu. Rev. Immunol. 1995, 13, 61-92.

[10] M. Hassan, M. Kjos, I. F. Nes, D. B. Diep, F. Lotfipour, J. Appl. Microbiol. 2012, 113, 723-736.

[11] J. Ravensdale, Z. Wong, F. O'Brien, K. Gregg, Front. Microbiol. 2016, 7 , DOI 10.3389/fmicb.2016.01745.

[12] M. N. Melo, R. Ferre, M. A. R. B. Castanho, Nat. Rev. Microbiol. 2009 7, 245-250.

[13] A. J. Verkleij, R. F. Zwaal, B. Roelofsen, P. Comfurius, D. Kastelijn, L. L. van Deenen, Biochim. Biophys. Acta 1973, 323, 178-193.

[14] A. K. Marr, W. J. Gooderham, R. E. Hancock, Curr. Opin. Pharmacol. 2006, 6, 468-472.

[15] A. S. Ripka, D. H. Rich, Curr. Opin. Chem. Biol. 1998, 2, 441-452.

[16] D. L. Steer, R. A. Lew, P. Perlmutter, A. I. Smith, M.-I. Aguilar, Curr Med. Chem. 2002, 9, 811-822.

[17] J. A. Patch, A. E. Barron, Curr. Opin. Chem. Biol. 2002, 6, 872-877.

[18] P. Méndez-Samperio, Infect. Drug Resist. 2014, 7, 229-237.

[19] D. Seebach, M. Overhand, F. N. M. Kühnle, B. Martinoni, L. Oberer, U. Hommel, H. Widmer, Helv. Chim. Acta 1996, 79, 913-941.
[20] S. H. Gellman, Acc. Chem. Res. 1998, 31, 173-180.

[21] E. A. Porter, B. Weisblum, S. H. Gellman, J. Am. Chem. Soc. 2002, 124 7324-7330.

[22] P. I. Arvidsson, N. S. Ryder, H. M. Weiss, G. Gross, O. Kretz, R. Woessner, D. Seebach, Chembiochem 2003, 4, 1345-1347.

[23] D. Seebach, A. K. Beck, D. J. Bierbaum, Chem. Biodivers. 2004, 1, 1111-1239.

[24] M. A. Schmitt, B. Weisblum, S. H. Gellman, J. Am. Chem. Soc. 2007, 129, 417-428.

[25] B. Legrand, L. Mathieu, A. Lebrun, S. Andriamanarivo, V. Lisowski, N. Masurier, S. Zirah, Y. K. Kang, J. Martinez, L. T. Maillard, Chem. Eur. J. 2014, 20, 6713-6720.

[26] I. M. Mándity, A. Monsignori, L. Fülöp, E. Forró, F. Fülöp, Chem. Eur. J. 2014, 20, 4591-4597.

[27] B. Legrand, C. André, L. Moulat, E. Wenger, C. Didierjean, E. Aubert, M. C. Averlant-Petit, J. Martinez, M. Calmes, M. Amblard, Angew. Chem. Int. Ed. Engl. 2014, 53, 13131-13135.

[28] I. M. Mándity, F. Fülöp, Expert Opin. Drug Discov. 2015, 10, 1163-1177.

[29] Y. Li, H. Wu, P. Teng, G. Bai, X. Lin, X. Zuo, C. Cao, J. Cai, J. Med. Chem. 2015, 58, 4802-4811.

[30] B. Legrand, C. André, L. Moulat, C. Didierjean, P. Hermet, J.-L. Bantignies, J. Martinez, M. Amblard, M. Calmès, Chem. Eur. J. 2016, 22, 11986-11990.

[31] I. M. Mándity, I. Nekkaa, G. Paragi, F. Fülöp, ChemistryOpen 2017, 6 , 492-496.

[32] B. F. Fisher, S. H. Hong, S. H. Gellman, J. Am. Chem. Soc. 2017, 139, 13292-13295.

[33] T. Godballe, L. L. Nilsson, P. D. Petersen, H. Jenssen, Chem. Biol. Drug Des. 2011, 77, 107-116.

[34] N. P. Chongsiriwatana, J. A. Patch, A. M. Czyzewski, M. T. Dohm, A. Ivankin, D. Gidalevitz, R. N. Zuckermann, A. E. Barron, Proc. Natl. Acad. Sci. U. S. A. 2008, 105, 2794-2799.

[35] M. L. Huang, S. B. Y. Shin, M. A. Benson, V. J. Torres, K. Kirshenbaum, ChemMedChem 2012, 7, 114-122.

[36] R. Kapoor, M. W. Wadman, M. T. Dohm, A. M. Czyzewski, A. M. Spormann, A. E. Barron, Antimicrob. Agents Chemother. 2011, 55, 3054-3057.

[37] S. W. Shuey, W. J. Delaney, M. C. Shah, M. A. Scialdone, Bioorg. Med. Chem. Lett. 2006, 16, 1245-1248.

[38] C. A. Olsen, G. Bonke, L. Vedel, A. Adsersen, M. Witt, H. Franzyk, J. W Jaroszewski, Org. Lett. 2007, 9, 1549-1552.

[39] A. Violette, S. Fournel, K. Lamour, O. Chaloin, B. Frisch, J.-P. Briand, H. Monteil, G. Guichard, Chem. Biol. 2006, 13, 531-538.

[40] A. Salaün, M. Potel, T. Roisnel, P. Gall, P. Le Grel, J. Org. Chem. 2005, 70, 6499-6502.

[41] A. Salaün, A. Favre, B. Le Grel, M. Potel, P. Le Grel, J. Org. Chem. 2006, 71, 150-158.

[42] C. Mocquet, A. Salaün, P. Claudon, B. Le Grel, M. Potel, G. Guichard, B. Jamart-Grégoire, P. Le Grel, J. Am. Chem. Soc. 2009, 131, 1452114525.

[43] O. Busnel, L. Bi, M. Baudy-Floc'h, Tetrahedron Lett. 2005, 46, 70737075.

[44] O. Busnel, L. Bi, H. Dali, A. Cheguillaume, S. Chevance, A. Bondon, S. Muller, M. Baudy-Floc'h, J. Org. Chem. 2005, 70, 10701-10708.

[45] O. Busnel, M. Baudy-Floc'h, Tetrahedron Lett. 2007, 48, 5767-5770.

[46] Laurencin, M., Bauchat, P., Baudy-Floc'h, M., Synthesis 2009, 10071013.

[47] H. Dali, O. Busnel, J. Hoebeke, L. Bi, P. Decker, J.-P. Briand, M. Baudy Floc'h, S. Muller, Mol. Immunol. 2007, 44, 3024-3036.

[48] K. Kisseljova, A. Kuznetsov, M. Baudy-Floc'h, J. Järv, Bioorganic Chem. 2011, 39, 133-137.

[49] C. Neveu, B. Lefranc, O. Tasseau, J.-C. Do-Rego, A. Bourmaud, P. Chan, P. Bauchat, O. Le Marec, J. Chuquet, L. Guilhaudis, et al., J. Med. Chem. 2012, 55, 7516-7524.

[50] M. Laurencin, B. Legrand, E. Duval, J. Henry, M. Baudy-Floc'h, C. Zatylny-Gaudin, A. Bondon, J. Med. Chem. 2012, 55, 2025-2034.

[51] M. Laurencin, M. Amor, Y. Fleury, M. Baudy-Floc'h, J. Med. Chem. 2012, 55, 10885-10895.

[52] O. Solecki, A. Mosbah, M. Baudy Floc'h, B. Felden, Chem. Biol. 2015 22, 329-335.

[53] S. Fernandez-Lopez, H. S. Kim, E. C. Choi, M. Delgado, J. R. Granja, A Khasanov, K. Kraehenbuehl, G. Long, D. A. Weinberger, K. M. Wilcoxen, et al., Nature 2001, 412, 452-455.

[54] S.-B. T. A. Amos, L. S. Vermeer, P. M. Ferguson, J. Kozlowska, M. Davy, T. T. Bui, A. F. Drake, C. D. Lorenz, A. J. Mason, Sci. Rep. 2016, 6, DOI 10.1038/srep37639.

[55] K. J. Cutrona, B. A. Kaufman, D. M. Figueroa, D. E. Elmore, FEBS Lett. 2015, 589, 3915-3920.

[56] D. Giménez, C. Andreu, M. del Olmo, T. Varea, D. Diaz, G. Asensio, Bioorg. Med. Chem. 2006, 14, 6971-6978. 
[57] L. M. Gottler, H.-Y. Lee, C. E. Shelburne, A. Ramamoorthy, E. N. G. Marsh, ChemBioChem 2008, 9, 370-373.

[58] B. Skerlavaj, M. Benincasa, A. Risso, M. Zanetti, R. Gennaro, FEBS Lett. 1999, 463, 58-62.

[59] M. Hartmann, M. Berditsch, J. Hawecker, M. F. Ardakani, D. Gerthsen, A. S. Ulrich, Antimicrob. Agents Chemother. 2010, 54, 3132-3142.

[60] M. Sisido, S. Egusa, Y. Imanishi, J. Am. Chem. Soc. 1983, 105, 1041 1049.

[61] M. Sisido, S. Egusa, Y. Imanishi, J. Am. Chem. Soc. 1983, 105, 40774082.

[62] M. Dathe, H. Nikolenko, J. Klose, M. Bienert, Biochemistry (Mosc.) 2004, 43, 9140-9150.

[63] J.-M. Wu, S.-Y. Wei, H.-L. Chen, K.-Y. Weng, H.-T. Cheng, J.-W. Cheng, Biopolymers 2007, 88, 738-745.

[64] S. Choi, W. Jeong, S.-K. Kang, M. Lee, E. Kim, D. Y. Ryu, Y. Lim, Biomacromolecules 2012, 13, 1991-1995.

[65] I. Wiegand, K. Hilpert, R. E. W. Hancock, Nat. Protoc. 2008, 3, 163-175.

[66] M. D. Pelta, H. Barjat, G. A. Morris, A. L. Davis, S. J. Hammond, Magn. Reson. Chem. 1998, 36, 706-714.
[67] B. Legrand, M. Laurencin, J. Sarkis, E. Duval, L. Mouret, J.-F. Hubert, M. Collen, V. Vié, C. Zatylny-Gaudin, J. Henry, et al., Biochim. Biophys. Acta 2011, 1808, 106-116.

[68] C. S. Johnson, Prog. Nucl. Magn. Reson. Spectrosc. 1999, 34, 203256

[69] B. A. Johnson, R. A. Blevins, J. Biomol. NMR 1994, 4, 603-614.

[70] K. Wüthrich, "Wiley: NMR of Proteins and Nucleic Acids," 1986.

[71] Case D.A., Betz R.M., Cerutti D.S., Cheatham T.E., III, Darden T.A. Duke R.E., Giese T.J., Gohlke H., Goetz A.W., Homeyer N., Izadi S., Janowski P., Kaus J., Kovalenko A., Lee T.S., LeGrand S., Li P., Lin C., Luchko T., Luo R., Madej B., Mermelstein D., Merz K.M., Monard G., Nguyen H., Nguyen H.T., Omelyan I., Onufriev A., Roe D.R., Roitberg A., Sagui C., Simmerling C.L., Botello-Smith W.M., Swails J., Walker R.C., Wang J., Wolf R.M., Wu X., Xiao L. and Kollman P.A., AMBER 2016, University of California, San Francisco, 2016.

[72] R. Koradi, M. Billeter, K. Wüthrich, J. Mol. Graph. 1996, 14, 51-55, 2932. 


\section{FULL PAPER}

Variation of side chains of $\alpha / a z a-\beta^{3}$

Cyclic Antimicrobial Peptides to

modulate their activity and selectivity. 